\title{
Towards Developing Successful E-Government Websites
}

\author{
Osama Rababah $^{1}$, Thair Hamtini ${ }^{2}$, Osama Harfoushi ${ }^{1}$, Bashar Al-Shboul ${ }^{1}$, Ruba Obiedat $^{1}$, \\ Sahem Nawafleh ${ }^{3}$
}

\begin{abstract}
${ }^{1}$ Department of Business Information Technology, King Abdullah II School for Information Technology, The University of Jordan, Amman, Jordan; ${ }^{2}$ Department of Computer Information System, King Abdullah II School for Information Technology, The University of Jordan, Amman, Jordan; ${ }^{3}$ Department of Management Information System, University of Petra, Amman, Jordan.

Email: o.rababah@ju.edu.jo,thamtini@ju.edu.jo, o.harfoushi@ju.edu.jo,b.shboul@ju.edu.jo,r.obiedat@ju.edu.jo, snawafleh@uop.edu.jo
\end{abstract}

Received September $30^{\text {th }}$, 2013; revised October $24^{\text {th }}, 2013$; accepted October $31^{\text {st }}, 2013$

Copyright (c) 2013 Osama Rababah et al. This is an open access article distributed under the Creative Commons Attribution License, which permits unrestricted use, distribution, and reproduction in any medium, provided the original work is properly cited.

\begin{abstract}
Quality is a key factor to ensuring success of e-government websites. Therefore, a definition for high-quality e-government website is required, as well as, an e-government system's quality evaluation methodology. This paper identifies quality attributes that are required to assess the quality of an e-government website, which should be considered by developers during the development of e-government applications. The primary goals are identifying, qualifying, categorizing, and ranking these factors, and then defining the interrelations among these quality factors.
\end{abstract}

Keywords: Web Application Development; E-Government; Quality Evaluation

\section{Introduction}

An e-government website forms a significant part of the government framework in advanced countries. It offers services to people in a context of advanced information technology, and new public management. Ensuring quality through website evaluation arises from the fact that an e-government website is the most important channel for public services delivery, and citizen-government interaction. Furthermore, the need to justify government investment that makes web-based service delivery possible is yet another reason for website quality assurance.

Past researches show that the website evaluation depends on multiple factors (e.g. download delay, errors in pages, broken links, server response time) that can be measured by web diagnostic $[1,2]$. Since government sites are becoming increasingly complex, an integral quantitative evaluation process regarding all relevant quality characteristics is also a complex issue. This is caused by the large amount of intervening characteristics, and by the complex logic relationships among attributes and characteristics. Besides, some relevant attributes to evaluate cannot objectively be measured so that they only can be included after a subjective measurement made by expert evaluators [3].

Most of the official government websites only offer basic information for visitors, without always paying attention to the usability, accessibility, and content management of the website. For example, making government services and information on the e-government websites is not equal to the successful access by users; especially for persons with disability [4]. It is frequently the case for people to visit a website which is poorly structured, difficult to navigate and unfriendly for readers. Some sites take a long time to download content, which makes users become impatient and leave. Those sites are often developed by people who have the perception that a quality site is the one that demonstrates the latest multimedia and animation effects [5].

\section{Identifying Quality Factor}

In this paper, the ISO/IEC 9126 was used as a base model to identify the basic e-government website quality factors. The ISO/IEC 9126 standard was developed in 1991 to provide the framework for evaluating software quality [6].

The model describes an internal and external software quality. The internal software quality is developer oriented derived from the product itself to satisfy end users' requirements. On the other hand, the external software quality provides an appreciation of the quality as seen from a user's perspective. Both the internal and external software qualities are prescribed in six factors (i.e. func- 
tionality, portability, maintainability, efficiency, usability and reliability), each of which is further decomposed into sub-factors. The model is illustrated in Figure 1.

As the figure shows, modifications on the ISO/IEC 9126 hierarchy were done as our research shows the necessity of including more characteristics and sub-characteristics after investigation, and receiving experts' feedbacks through reviews and interviews. In particular, security, availability, readability, content, navigation and trustworthiness were added as main factors. Security subfactor was removed from "Functionality" and was considered as a "main" factor that contains many sub-factors (i.e. Authentication, Privacy, and Access Control) [7].

Website content is an important factor which deals with the characteristics of website information since it is the major source of value to customers [8]. Table 1 lists the factors used with a short explanation of each factor.

Based on the academic research exercised, it was thought that a list of twelve factors will satisfy an assessment of the quality of E-government websites. These factors then were extended with sub-factors. The complete list of those forty-nine sub-factors is displayed within quality factors in Table 1.

\section{Qualifying and Rating}

A rating system for the factors was built in order to reflect the relative importance of the different sub-factors within a main factor. The results were generated based on questionnaires from expert specialists in e-government website development.

The survey covered eighteen experts from IT companies and government institutes in Jordan, most of them acquired development expertise, solid technical background, and a wide experience in designing and developing websites. Experts were distributed over five private companies and three government institutes. They were basically asked to respond to the questionnaire by ordering the sub-factors within each factor according to the importance of their contribution towards their factor.

One randomly selected expert was identified to validate the content and style of the questionnaire to make sure that the questions were clear and complete, the questionnaire' response was excluded from further analysis.

Given factor S having four sub-factors, namely: SS1 to SS4, each participant was asked to rate each sub-factor according to its importance in influencing $S$, where 1 was the most important and 4 was the least. Sub-factors with fewer responses than $50 \%$ were removed from the analysis, and the average of received responses was calculated to fill in the gaps of any missing observations. Once all results were collected, a weighting scheme was applied to reflect the rating of the different sub-factors based on the following formula [9]:

Sub-factor Percent Importance $=100-(M / N) * 100$ (1) where $M$ represents the average rating received on a subfactor and $N$ represents the total number of sub-factors for a given factor. The subtraction from 100 is to reverse the rating scale of the questionnaire so that the questionnaire rating of " 1 " has the highest percentage importance. The final rating achieved has the highest percentage given to the most important sub-factor, proceeding to the least important in a descending fashion. One drawback to this method is that the final rating obtained for each sub-factor is dependent on the number of sub-factors in each group; therefore, it affects inter-factor correlations. To compensate for this problem, a second group of experts were asked to assess the appropriateness of the correlations as explained in the next section.

Table 1 shows the rating received by each sub factor within each factor proceeding from the most important sub-factor to the least important in a descending fashion.

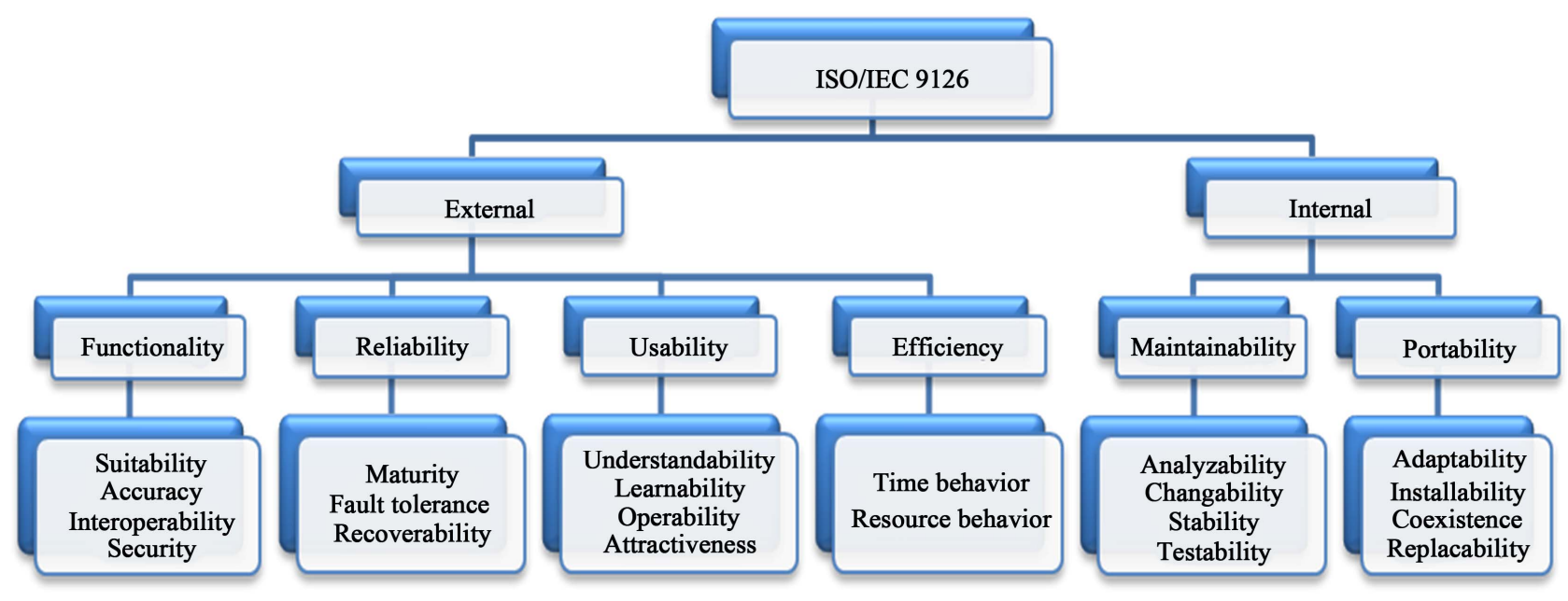

Figure 1. The ISO/IEC 9126. 
Table 1. Identified quality sub-factors.

\begin{tabular}{|c|c|c|c|c|c|}
\hline Quality Sub-factor & Rank & Quality Sub-factor & Rank & Quality Sub-factor & Rank \\
\hline \multicolumn{2}{|l|}{ Functionality } & \multicolumn{2}{|l|}{ Content } & \multicolumn{2}{|l|}{ Usability } \\
\hline Accuracy & 60 & Correctness & 67 & Understandability & 70 \\
\hline Suitability & 47 & Updated & 50 & Response Time & 63 \\
\hline Interoperability & 25 & Completeness & 46 & Learnability & 61 \\
\hline Flexibility & 22 & Relevancy & 44 & Interactivity & 54 \\
\hline \multicolumn{2}{|l|}{ Reliability } & User-Oriented & 36 & Operability & 52 \\
\hline Maturity & 43 & Concise Content & 36 & Helpfulness & 50 \\
\hline Fault Tolerance & 29 & Intelligibility & 24 & Attractiveness & 48 \\
\hline Recoverability & 27 & Navigation & & Language & 48 \\
\hline \multicolumn{2}{|l|}{ Security } & Navigation Structure & 55 & Customizability & 39 \\
\hline Privacy & 39 & Absence Of Navigation Errors & 42 & Accessible for users with disabilities & 35 \\
\hline Authentication & 29 & Links Visibility & 41 & Download Facility & 28 \\
\hline Access Control & 24 & Minimal Path & 32 & Printing Facility & 27 \\
\hline \multicolumn{2}{|l|}{ Efficiency } & External and Internal Links & 27 & \multicolumn{2}{|l|}{ Maintainability } \\
\hline Time Behavior & 44 & Readability & & Stability & 59 \\
\hline Resource Utilization & 15 & Clarity & 51 & Changeability & 40 \\
\hline \multicolumn{2}{|l|}{ Availability } & Language Correctness & 25 & Analyzability & 28 \\
\hline 24/7 Readiness & 41 & Style Uniformity & 24 & Testability & 26 \\
\hline \multirow[t]{3}{*}{ Cross Browser Support } & 9 & Trustworthiness & & \multicolumn{2}{|l|}{ Portability } \\
\hline & & Correctness & 32 & Adaptability & 26 \\
\hline & & Completeness & 12 & Conformance & 24 \\
\hline
\end{tabular}

\section{Factors Relations}

In order to build a reliable model, it is important to figure out the different inferences and causal relations between the quality factors [10]. Statistical correlation was used in analyzing the data obtained from the responses to the questionnaire to establish initial inter-factor relations. Correlation is not an indication of cause-and-effect relationships [11] where changes in one variable impacts, and is the direct cause of changes in the correlated variable. Correlations merely indicate whether two variables are in harmony in terms of movement. However, a harmony in movement in either the same direction or opposite (inverse) direction provides insight into possible cause-and-effect relationships. In this paper, correlations are used with rating scales, but with care. After the completion of identifying the factors' significant inter-relations, the results were reviewed by a panel of experts to ensure they were comfortable with the results.

The validation of each possible relationship was carried out using a panel of experts to analyze the results of the correlation analysis to draw conclusions about which viable inter-dependencies exist amongst sub-factors. The panel members were invited to a group discussion on what would be the relevant and important relationships among the sub-factors. Using Martin's approach [12], a stepwise model selection technique combining forward selection and backwards elimination was used. Every panel member was asked to select the best causal relationship, in their view. The selection was iterated one relationship at a time in a round-robin approach. Not knowing when a cessation would be reached in this process, the members continued till their own point of satisfaction was reached and no further selection was added to their derived list. At that point a reversal elimination process started where each member was asked to return the least desired relation from their possession. The process continued in a round-robin fashion until the panel collectively retained $50 \%$ of the initially selected relations. The exercise was concluded at that point. Table 2 shows the results of the selection process. 
Table 2. Final selection $f$ sub-factor interdependencies identified quality sub-factors.

\begin{tabular}{ccc}
\hline Sub-Factor & & Sub-Factor \\
\hline Absence of & influences & Correctness \\
Navigation Errors & influences & Maturity \\
Authentication & influences & Privacy \\
Concise Content & influences & Accuracy \\
& & Correctness \\
Correctness & influences & Updated \\
Links Visibility & influences & Accuracy \\
Navigation Structure & influences & Completeness \\
Recoverability & influences & Cof Navigation Errors \\
Stability & influences & Foult Tolerance \\
Testability & influences & 24/7 Readiness \\
Updated & influences & Analyzability \\
influences & Accuracy \\
\hline & & Language \\
\hline & &
\end{tabular}

The same panel of three experts was invited to another exercise to perform interrelation analysis at the quality factors level. All the possible factor relationships, as shown in Table 3, were projected at a display wall. The panel members were asked to assess the relation "cells" and provide a score of 0 to 2 where " 2 " indicates the presence of strong causal relations and a "0" the lack of such a relationship. Table 3 lists possible relations among factors and the rating results received. Table 4 shows the resultant relations inferred.

\section{Conclusion}

This paper has identified and ranked the factors and subfactors that contribute towards the quality of an e-government website. Furthermore, the relationships among these factors showing which factors influence others have been derived. The results provide an important foundation for the understanding of quality in e-government websites that will allow developers to assess the strengths and weaknesses of their sites in order to know where to focus further development to achieve the high quality for e-government success $[13,14]$.

Table 3. Factors polled relations.

\begin{tabular}{|c|c|c|c|c|c|c|c|c|c|c|c|c|}
\hline 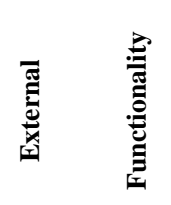 & 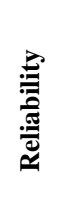 & 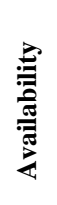 & 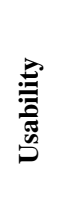 & 总 & 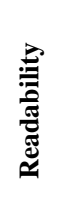 & $\begin{array}{l}\vec{E} \\
\text { Ü }\end{array}$ & 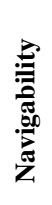 & ڤ్ & 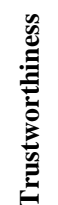 & & 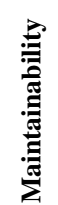 & 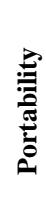 \\
\hline
\end{tabular}

External

Functionality

\begin{tabular}{|c|c|c|c|c|c|c|c|c|c|c|c|}
\hline Reliability & 4 & & & & & & & & & & \\
\hline Availability & 1 & 5 & & & & & & & & & \\
\hline Usability & 4 & 1 & 1 & & & & & & & & \\
\hline Efficiency & 2 & 2 & 3 & 3 & & & & & & & \\
\hline Readability & 4 & 1 & $\mathbf{0}$ & 6 & 3 & & & & & & \\
\hline Content & 2 & 2 & $\mathbf{0}$ & 5 & 4 & 6 & & & & & \\
\hline Navigability & 3 & 1 & 1 & 4 & 4 & 5 & 3 & & & & \\
\hline Security & 3 & 4 & 1 & 3 & 3 & $\mathbf{0}$ & 3 & 2 & & & \\
\hline rustworthiness & 3 & 6 & 6 & 4 & 2 & 3 & 5 & 3 & 6 & & \\
\hline \multicolumn{12}{|l|}{ Internal } \\
\hline Maintainability & 2 & 4 & 4 & $\mathbf{0}$ & $\mathbf{0}$ & $\mathbf{0}$ & $\mathbf{0}$ & 2 & 2 & 1 & \\
\hline Portability & 1 & 3 & 3 & 2 & 1 & 3 & 0 & 4 & 0 & 1 & 4 \\
\hline
\end{tabular}


Table 4. Finalized selection of factor interdependencies.

\begin{tabular}{|c|c|c|}
\hline Factor & & Factor \\
\hline Reliability & influences & Functionality \\
\hline Availability & influences & Reliability \\
\hline Usability & influences & Functionality \\
\hline Readability & influences & $\begin{array}{c}\text { Functionality } \\
\text { Usability }\end{array}$ \\
\hline & & Usability \\
\hline Content & influences & $\begin{array}{l}\text { Efficiency } \\
\text { Readability }\end{array}$ \\
\hline & & Usability \\
\hline Navigability & influences & $\begin{array}{l}\text { Efficiency } \\
\text { Readability }\end{array}$ \\
\hline Security & influences & Reliability \\
\hline & & $\begin{array}{l}\text { Reliability } \\
\text { Availability }\end{array}$ \\
\hline Trustworthiness & influences & Usability \\
\hline & & $\begin{array}{l}\text { Content } \\
\text { Security }\end{array}$ \\
\hline Maintainability & influences & $\begin{array}{l}\text { Reliability } \\
\text { Availability }\end{array}$ \\
\hline Portability & influences & $\begin{array}{c}\text { Navigability } \\
\text { Maintainability }\end{array}$ \\
\hline
\end{tabular}

\section{Acknowledgements}

This work was supported by The University of Jordan.

\section{REFERENCES}

[1] Y. Rogers, H. Sharp and J. Preece, "Interaction Design: Beyond Human Computer Interaction,” 2nd Edition, Wily, New Jersey, 2007.

[2] H. Jati and D. Dominic, "Quality Evaluation of e-Government Website Using Web Diagnostic Tools: Asian Case,” International Conference on Information Management and Engineering (ICIME), Kuala Lumpur, 3-5 April 2009, pp. 85-89.
[3] D. T. Green and J. M. Pearson, "Integrating Website Usability with the Electronic Commerce Acceptance Model," Behaviour \& Information Technology, Vol. 30, No. 2, 2011, pp. 181-199. http://dx.doi.org/10.1080/01449291003793785

[4] Georgia Tech Research Institute, "Overview of State Accessibility Laws, Policies, Standards and Other Resources,” 2012.

http://accessibility.gtri.gatech.edu/sitid/stateLawAtGlance .php

[5] A. Olalere and J. Lazar, "Accessibility of US Federal Government Home Pages: Section 508 Compliance and Site Accessibility Statements," Government Information Quarterly, Vol. 28, No. 3, 2011, pp. 303-309. http://dx.doi.org/10.1016/j.giq.2011.02.002

[6] ISO, "ISO/IEC IS 9126: Software Product EvaluationQuality Characteristics and Guidelines for Their Use,” International Organizational for Standardization, Geneva, 1991.

[7] D. L. Baker, "Advancing E-Government Performance in the United States through Enhanced Usability Benchmarks," Government Information Quarterly, Vol. 26, No. 1, 2009, pp. 82-88. http://dx.doi.org/10.1016/j.giq.2008.01.004

[8] L. Hasan and E. Abuelrub, “Assessing the Quality of Websites,” Applied Computing and Informatics, Vol. 9, No. 1, 2011, pp. 11-29. http://dx.doi.org/10.1016/j.aci.2009.03.001

[9] O. Rababah, "Quality Assessment of E-Commerce Websites Using Bayesian Belief Network,” Loughborough University, Leicestershire, 2007.

[10] T. L. Eleanor, “A Measure of Web Site Quality,” Management Department, Washburn Hall-WebQual ${ }^{\mathrm{TM}}, 1999$.

[11] StatSoft, “Basic Statistics Introduction,” 2012. http://www.statsoft.com/textbook/stbasic.htm

[12] M. Martin, “It’s Like...You Know: The Use of Analogies and Heuristics in Teaching Introductory Statistical Methods,” Journal of Statistics Education, Vol. 11, No. 2, 2003.

[13] M. J. Kargar, A. R. Ramli, H. Ibrahim and S. B. Noor, “Towards a Practical and Valid Model for Assessing Quality of Information on the Web," International Review on Computers and Software, Vol. 2, No. 2, 2007, pp. 80-88.

[14] T. Hamtini and O. Rababa, "A Graphical Model for Assessing the Quality of E-Commerce Systems," International Review on Computers and Software, Vol. 7, No. 1, 2011, pp. 9-17. 